\title{
Triggers and cues that activate antibiotic production by actinomycetes
}

\author{
Hua Zhu • Stephanie K. Sandiford • \\ Gilles P. van Wezel
}

Received: 7 May 2013/Accepted: 30 June 2013/Published online: 2 August 2013

(C) Society for Industrial Microbiology and Biotechnology 2013

\begin{abstract}
Actinomycetes are a rich source of natural products, and these mycelial bacteria produce the majority of the known antibiotics. The increasing difficulty to find new drugs via high-throughput screening has led to a decline in antibiotic research, while infectious diseases associated with multidrug resistance are spreading rapidly. Here we review new approaches and ideas that are currently being developed to increase our chances of finding novel antimicrobials, with focus on genetic, chemical, and ecological methods to elicit the expression of biosynthetic gene clusters. The genome sequencing revolution identified numerous gene clusters for natural products in actinomycetes, associated with a potentially huge reservoir of unknown molecules, and prioritizing them is a major challenge for in silico screening-based approaches. Some antibiotics are likely only expressed under very specific conditions, such as interaction with other microbes, which explains the renewed interest in soil and marine ecology. The identification of new gene clusters, as well as chemical elicitors and culturing conditions that activate their expression, should allow scientists to reinforce their efforts to find the necessary novel antimicrobial drugs.
\end{abstract}

Keywords Silent antibiotic - Elicitor - Soil ecology · Natural product · Genome mining - Streptomyces

Special issue: Genome Mining for Natural Products Discovery.

H. Zhu · S. K. Sandiford · G. P. van Wezel $(\bowtie)$

Molecular Biotechnology, Institute of Biology, Leiden

University, Sylviusweg 72, 2333 BE Leiden, The Netherlands

e-mail: g.wezel@biology.leidenuniv.nl

\section{Introduction}

The discovery of penicillin by Sir Alexander Fleming [42] opened up a completely new era of chemotherapy. The discovery of numerous antibiotics from primarily soil microorganisms and the near eradication of diseases such as tuberculosis led to the concept that infectious diseases may be something of the past [53]. However, the emergence of infectious diseases involving multidrug resistant (MDR) bacterial pathogens since the 1980s means that bacterial infections are still a major threat for human health. According to the World Health Organization (WHO), around 440,000 new cases of multidrug-resistant tuberculosis (MDR-TB) are found annually, causing more than 150,000 deaths. Extensively drug-resistant tuberculosis (XDR-TB) has now been reported in 64 countries to date [159]. The explosive increase in infections by pathogens such as methicillin-resistant Staphylococcus aureus (MRSA), vancomycin-resistant Enterococcus faecium (VRE) and fluoroquinolone-resistant Pseudomonas aeruginosa is estimated to cause approximately 19,000 deaths per year in the US [70], and the most recent occurrence of pan-antibiotic-resistant infections pose the grave threat of completely untreatable infections [8].

Filamentous microorganisms (fungi and bacteria of the order of Actinomycetales) are the major source of secondary metabolites, producing some $90 \%$ of all known antibiotics [15, 100]. Some two-thirds of all antibiotics are produced by actinomycetes, the majority of which by members of the genus Streptomyces. Until now, tens of thousands of natural antimicrobial products have been isolated from microbial sources, and still these likely represent only a tiny portion of the repertoire of bioactive compounds that can potentially be produced $[15,100]$. Also, the microbial biodiversity of soil and marine 
environments is enormous, with millions of fungi and bacteria likely to be present, of which we have seen only the tip of the iceberg [119].

The decline of high-throughput screening of antibiotics and silent gene clusters

As early as the 1990s, it was predicted that the future of antibiotic discovery might not lie in high-throughput screening (HTS; [71]) or combinatorial chemistry [97]. Perhaps the best known example is the HTS effort conducted by GlaxoSmithKline, where millions of compounds were screened in many HTS campaigns, with only marginal success [117]. Underlying causes for the lack of success include the fact that many of the essential targets in the bacterial cell are not "druggable", that the molecules identified by HTS do not always have the ideal drug properties as defined in Lipinski's rule-of-five [78], and that molecules in compound libraries are biased for use in pharmacology and do not have the molecular complexity of naturally occurring secondary metabolites.

Antibiotics not yet discovered have been estimated to be produced at frequencies of less than one per million in fermentation broths from randomly chosen actinomycetes $[10,12]$. The situation is often hindered by the fact that often actinomycetes produce high levels of several antibiotics, which will obscure the production of less well expressed or less bioactive antibiotics. How can we stand a chance to find anything novel when BigPharma fails to find them in their comprehensive screening efforts? For one, actinomycetes are soil or marine bacteria, and one approach most likely lies in the direction of ecology. In other words, if we understand the temporal and conditional cues that activate antibiotic production in situ, this can then be applied to improve screening efforts. A second aspect that is now available is the information derived from whole genome sequencing and the connected genomics technologies. Sequencing the genomes of actinomycetes established the presence of many more biosynthetic clusters for secondary metabolites than originally anticipated. For example, it has been known for decades from the pioneering work of David Hopwood and many of his colleagues that the model actinomycete Streptomyces coelicolor produces four antibiotics, namely actinorhodin (Act), undecylprodigiosin (Red), calcium-dependent antibiotic (Cda), and the plasmid-encoded methylenomycin (Mmy) [51, 53]. Still, despite 50 years of intensive research, it came as a complete surprise when the $S$. coelicolor genome sequence [14] revealed the presence of many previously unidentified biosynthetic gene clusters [25, 53], including one for a likely antibiotic called cryptic polyketide (Cpk; [116]). It rapidly became clear that other actinomycetes also have extensive arsenals of secondary metabolites [59, 109, 111, 112, 147]. It therefore appears that the potential of these organisms for novel drug production is much larger than originally anticipated. This has led to extensive research into the applied genomics relating to what is generally referred to as cryptic, silent, or sleeping antibiotics (reviewed in [46, 94, 99, 152, 169]).

Therefore, there are likely many yet-unidentified compounds out there, which were missed either because the gene clusters that specify them are not expressed at sufficiently high levels or because the compounds have lower specific activity than the readily screenable antibiotics and may require modification to become more active. Here we review in particular global approaches for antibiotic mining, with the activation of poorly expressed antibiotic biosynthetic gene clusters in mind.

\section{Regulation of antibiotic production}

The regulation of antibiotic production involves multiple regulatory cascades and networks. Knowledge on the regulatory genes can be applied in approaches to activate antibiotic production but is also very useful in terms of localizing biosynthetic gene clusters (see below). Although the number and variety of genes involved vary from species to species, certain features are common. Global regulators almost by definition have a wide-ranging impact on global transcription patterns, but also "cluster-situated regulators" (CSRs) may have a broader impact than only on the cluster they are associated with [58]. Genes involved in antibiotic production are generally organized in biosynthetic gene clusters, consisting of several transcription units. Besides the obvious advantage of coordinated control of biosynthesis, export, and resistance, the additional evolutionary driving force behind such linkage is most likely an ecological one, as it allows the transfer of complete gene clusters during genetic exchange in the habitat.

The act gene cluster as model system

Arguably the best studied antibiotic gene cluster is act in $S$. coelicolor, for the type-II PKS actinorhodin (Act). This genetic system is a beautiful illustration of the possible complexity of the regulatory networks involved in the control of antibiotic production, and we highlight common features to illustrate the relevant concepts, in particular because most pleiotropic regulators have an effect on Act production in $S$. coelicolor. For more extensive overviews of the control of antibiotic production, we refer to reviews elsewhere $[16,79,151]$. Several general themes related to the control of act production are highly relevant for approaches to wake up sleeping antibiotics, and are worked out in more detail in the following sections of this review. 
The act gene cluster consists of around 20 genes, organized in several transcription units [82]. ActII-ORF4 is the cluster-situated and pathway-specific regulator of the act gene cluster that binds to target sequences of the act promoters, with an N-terminal helix-turn-helix DNA binding domain and a $\mathrm{C}$-terminal transcriptional activation domain [62]. ActII-ORF4 is a member of a family of pathway-specific activator proteins termed Streptomyces antibiotic regulatory proteins or SARPs [160]. SARP regulators are typically expressed in a growth phase-dependent manner and at a high level [16], and there appears to be little or no control downstream. This is exemplified by promoter probing experiments using redD-the pathway-specific activator gene for the red cluster-as a reporter; which demonstrated that both timing and level of expression of the red cluster is directly proportional to the expression of RedD, even in early vegetative mycelia or in aerial hyphae, where the cluster is normally not expressed [154].

Many pleiotropic regulators characterized so far are required only under specific environmental conditions [17], and several of these control act gene expression. DasR is a GntR-family regulator that controls among others amino sugar metabolism and transport and the chitinolytic system $[29,30,124,140]$. DasR is a highly pleiotropic regulator, and in a recent environmental study, microarray data on the das $R$ null mutant in soil-grown cultures in the presence of chitin revealed some 700 genes that were differentially expressed [98]. DasR connects the control of primary and secondary metabolism by directly controlling the transcription of actII-ORF4, the pathway-specific activator gene for actinorhodin biosynthesis (Fig. 1), and redZ, a response regulator required for undecylprodigiosin production. The DasR regulon and its use as target for global approaches to induce antibiotic production is discussed in detail below.

AtrA is a TetR-family protein that is required for the transcription of actII-ORF4 [148], and in turn responds to the level of phosphate as it is repressed by the PhoRP system [130]. Further complexity is offered by Rok7B7, a member of the ROK family of proteins, which are

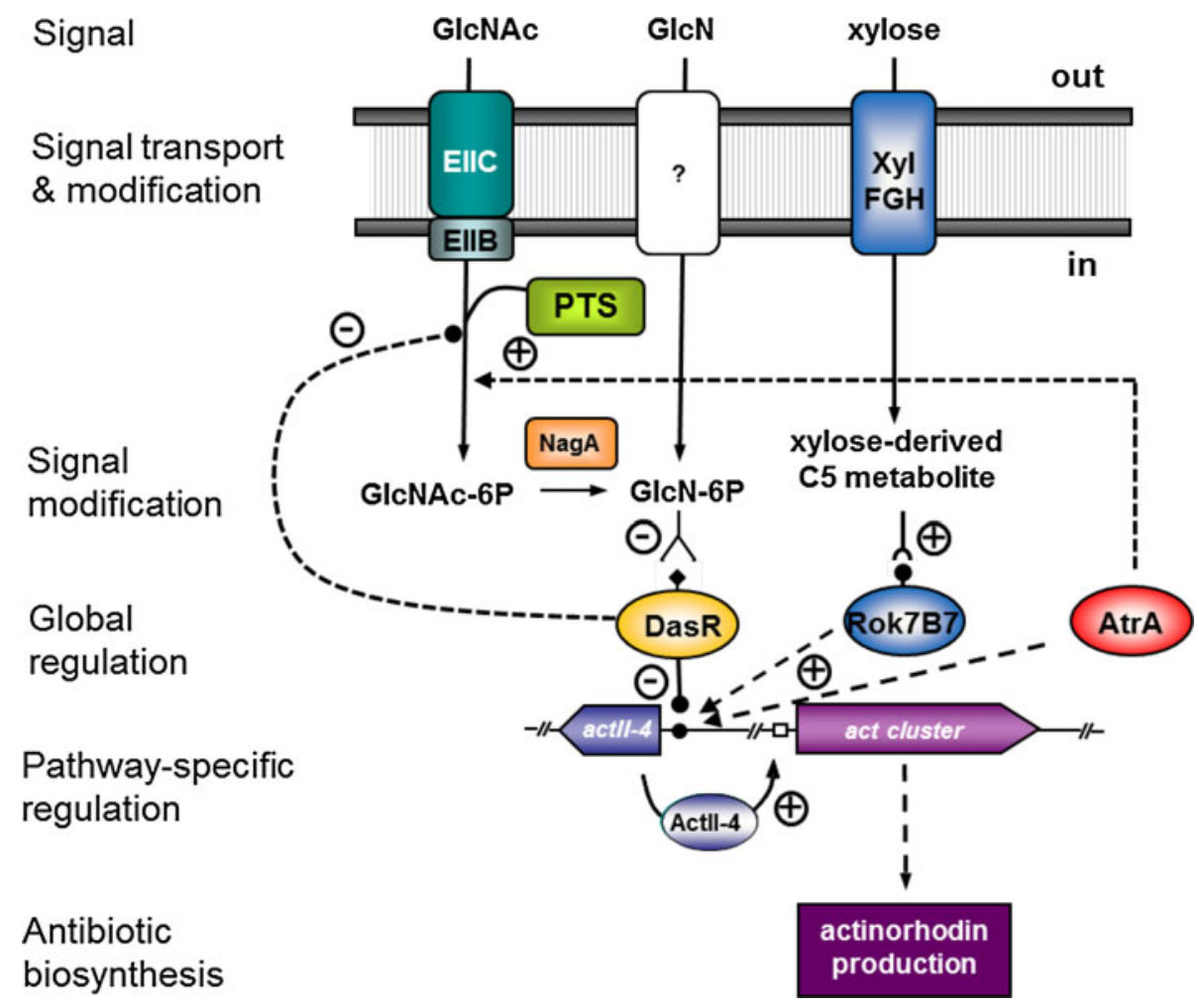

Fig. 1 Pleiotropic and nutrient-mediated control of actinorhodin production in S. coelicolor. $N$-acetylglucosamine (GlcNAc) enters the cell and is subsequently phosphorylated via the GlcNAc-specific phosphoenolpyruvate-dependent phosphotransferase system (PTS), composed of intracellular PTS proteins EI, HPr, and EIIA, and the GlcNAc-specific components EIIB (NagE2) and EIIC (NagF). Phosphoenolpyruvate (PEP) is the phosphodonor. $N$-acetylglucosamine-6-phosphate (GlcNAc-6P) is then deacetylated by GlcN-6P deacetylase NagA to glucosamine-6-phosphate (GlcN-6P), the effector molecule that inhibits DasR DNA-binding. This results in derepression of actII-ORF4, the pathway-specific transcriptional activator gene for the actinorhodin biosynthetic gene cluster. This represents a complete signaling cascade from extracellular nutrients to the activation of actinorhodin production. The global regulators AtrA and Rok7B7 have opposite activities to DasR, with AtrA and Rok7B7 both activating actinorhodin production, and at least AtrA also activating GlcNAc transport, thereby antagonizing DasR. Rok7B7 is likely activated by a xylose-derived C5 sugar transported via the $\mathrm{ABC}$ transporter XylFGH. For details and references, see the text. The effect of GlcNAc on antibiotic production is shown in Fig. 2 
predominantly sugar regulatory proteins and sugar kinases, including glucose kinase [146]. Rok7B7 pleiotropically affects primary and secondary metabolism, and is required for actinorhodin production [139]. Introduction of an ortholog of rok7B7 called rep, obtained from a metagenomic library, appeared to be an effective way of activating antibiotic production in S. coelicolor [90]. Recent evidence suggests that Rok7B7 may be activated by a derivative of the C5 sugar xylose [139]. The activity of DasR, Rok7B7, and perhaps also AtrA is subject to nutrient control at the posttranslational level, and the metabolic status of the cell will therefore largely determine their contributions to the control of antibiotic production.

Other pleiotropic antibiotic regulators involved in the control of actII-ORF4 are AfsR and PhoP. AfsR contains an N-terminal SARP domain and is conditionally required for Act and Red production [43]. AfsR binds to the promoter of the downstream located afsS (also called afsR2) and activates its transcription [75]. While the precise function of $a f s S$ is unclear, it activates antibiotic production in many streptomycetes, and is therefore an attractive target for the activation of antibiotic production. PhoP, which represses actinorhodin production in response to phosphate, probably acts indirectly, and perhaps by repressing afsS. The role of PhoP in the control of antibiotic production is discussed in more detail in the next section.

Interestingly, deletion of the gene for Streptomyces integration host factor (SIHF) also effects enhanced actinorhodin production [166]. IHF assists in cell processes that require higher-order protein complexes, e.g., DNA replication, transcriptional regulation, and site-specific recombination [44]. Again, the effect of sIHF on antibiotic production is most likely direct, as EMSAs showed direct binding to the redD promoter region [166]. Finally, the two-component system DraR-K controls antibiotic biosynthesis in S. coelicolor in response to high concentrations of nitrogen [168]. PhosphoDraR enhances the production of Act but represses yellow pigmented type I polyketide (yCPK) biosynthesis via direct control of the pathway-specific activator genes actII-ORF4 and $c p k O$, respectively, while repression of Red biosynthesis is indirect [168]. Besides the selection of regulatory proteins mentioned above, a surprisingly large number of other genes affect the expression of actII-ORF4 [79, 151]. This highlights the amazing regulatory complexity for a gene cluster that apparently specifies a compound with weak antibiotic activity, suggesting that actII-ORF4 and/or the act cluster may have a more important physiological role than currently anticipated.

Genetic control in response to carbon, nitrogen, and phosphorous

Most secondary metabolites are produced in a growth phase-dependent manner, typically during the onset of development, corresponding to transition phase and early stationary phase in submerged cultures. Nutrient composition and concentration within media not only affects growth rate but also influences complex changes in global gene regulation, reflecting the range of conditions that trigger the production of different antimicrobials in nature $[16,128,151]$.

Carbon sources have a major impact on the expression of biosynthetic genes and morphological development of microorganisms. Carbon catabolite repression (CCR) occurs when media contains mixtures of rapidly and slowly used carbon sources and is a regulatory mechanism commonly observed in bacteria [22, 45, 145]. After exhausting the preferred carbon source, bacteria turn to the "secondbest" carbon source, and this often correlates temporally with the onset of antibiotic production, which is associated with growth cessation [36]. Glucose is a preferred carbon source for many actinomycetes and effects global repression of antibiotic production [37, 118], which is why in industrial fermentations, polysaccharides (e.g., starch), oligosaccharides (e.g., lactose) and oils (e.g., soybean oil, methyloleate) are commonly used.

The central protein that controls CCR in streptomycetes is glucose kinase (Glk), with deletion of the gene for glucose kinase resulting in global derepression of carbon utilization [5, 6]. Glk expression is constitutive, and its activation takes place posttranslationally in glucose-grown cultures, but not when cultures are grown on non-repressing sugars [149]. This suggests that interfering with the activation of the CCR activity of Glk, while leaving glycolysis unchanged, should enable antibiotic production in glucose-grown cultures, which would be a major advantage for industrial fermentations. To address this, a comprehensive quantitative proteome analysis was performed on cultures of $S$. coelicolor and its glkA mutant grown in minimal media with mannitol or fructose and with or without additional glucose, which revealed the response of nearly all enzymes in central metabolism and most antibiotic-related pathways. This surprisingly showed that while CCR and inducer exclusion of the majority of the primary and secondary metabolic pathways was mediated in a Glk-dependent manner (as expected), glucose repression of the biosynthesis of the $\gamma$-butyrolactone Scb1 and the responsive $c p k$ gene cluster for the cryptic polyketide Cpk is independent of Glk [47]. Other cryptic pathways could perhaps also be controlled in an entirely different way, providing a possible new lead for the activation of poorly expressed antibiotics.

High concentrations of nitrogen sources such as ammonium or amino acids also suppress the biosynthesis of secondary metabolites $[1,86]$. Complex fermentation media therefore include proteins as nitrogen source and defined media slowly assimilated amino acids, so as to 
ensure optimal antibiotic production. For example, streptomycin production by Streptomyces griseus is favored by growth in both soybean meal and proline in combination with low concentrations of additional ammonium salts [39, 162]. Production of aminoglycoside antibiotics was also repressed by ammonium salts, whereas nitrate and certain amino acids stimulated their production [132].

Biosynthesis of antibiotics and other secondary metabolites is transcriptionally repressed by easily utilized phosphate sources [85]. The depletion of phosphate in the environment triggers the biosynthesis of secondary metabolites but represses growth [86]. Generally, phosphate concentrations above $0.5 \mathrm{mM}$ stimulate growth at the expense of secondary metabolism, while, conversely, below this threshold the production of secondary metabolites is favored, including antibiotic production [156]. This activation of antibiotic production is among others governed via autoregulatory signals [54, 101, 164]. A major system for the global control of gene expression in response to the phosphate concentration is the two-component regulatory system PhoRP [136]. PhoRP is widespread in prokaryotes and is involved in the control of antibiotic production in among others $S$. coelicolor and Streptomyces lividans (Act, Red; [129, 135]), S. griseus (candicidin; [87]), S. natalensis (pimaricin; [95]) and in Streptomyces rimosus (oxytetracycline; [92]), although phosphate-mediated repression is a general phenomenon [88].

Sensory histidine kinase PhoR is prevented from phosphorylating its cognate response regulator PhoP via its interaction with the high-affinity phosphate transport system Pst, which in turn is activated by PhoR. Thus, only little phosphate transporter is produced when sufficient phosphate is available. However, during phosphate limitation, PhoR is released and phosphorylates PhoP, resulting in enhanced phosphate transport and utilization [85, 136]. Recent global analysis of PhoP binding sites by immunoprecipitated genomic DNA hybridized to DNA microarrays (ChIP-chip) showed that besides controlling the phosphate regulon, PhoP also transiently shuts down central metabolic pathways [3]. PhoP directly controls the pathwayspecific regulatory gene $c d a R$ for Cda production in $S$. coelicolor, but control of actinorhodin and undecylprodigiosin production is most likely indirect, as there are no obvious PhoP-binding sites in the promoter regions of the pathway-specific regulatory genes actII-ORF4 and redD/ redZ, respectively, and PhoP failed to bind to the promoters [85]. However, PhoP may affect these antibiotics indirectly via the control of afsS [130].

In addition, PhoP plays a major role in the cross-talk between $\mathrm{N}$ - and P-metabolism, via the repression of $g \ln R$, for the global nitrogen regulator $\operatorname{GlnR}[89,126]$. Therefore, PhoP takes up a central role in the junction between primary and secondary metabolism, and targeting this system is an attractive approach to pleiotropically affect antibiotic production.

\section{Genetic tools for the activation of antibiotic production}

Enhanced expression of SARP regulators is an effective yet strain-specific approach for the overexpression of the gene clusters they control. However, the associated gene clusters are often "household" antibiotics, i.e., they are expressed under most growth conditions, typically during the transition from late exponential to stationary growth [16]. This suggests that most antibiotics specified by SARP-controlled gene clusters will have been identified in HTS screening efforts by BigPharma.

Recently, a new class of regulatory genes was identified, which encode proteins with similarity to LAL (Large ATP binding regulators of the LuxR family) proteins [72]. Constitutive expression of a pathway-specific LAL regulator as CSR for a giant $(150 \mathrm{~kb})$ type-I modular polyketide synthase (PKS) gene cluster in Streptomyces ambofaciens, resulted in the production of a number of novel 51-membered glycosylated macrolides, named stambomycins A-D [72]. Since genome sequencing identified LAL regulators that are associated with several yet unidentified gene clusters, constitutive expression of such CSRs represents a promising new approach for natural product discovery.

The enhanced expression of afsS appears to be an effective and generally applicable way of activating antibiotic production. Its enhanced expression stimulates antibiotic production in among others $S$. coelicolor [91], S. lividans [157], S. avermitilis [74], and S. noursei [131]. The overexpression of AfsR also increased antibiotic production, for example in S. coelicolor [43], S. peucetius [115], and $S$. venezuelae [81], which is perhaps mediated via activation of afsS [75]. The effect of the afsS ortho$\operatorname{logue} \operatorname{ssm} A$ on nistatin production by $S$. noursei suggests that perhaps afs $R S$ act in a carbon source-dependent manner [131].

\section{Ribosome engineering}

An effective and very promising way to activate antibiotic production is manipulation of the strains via so-called "ribosome-engineering", developed by Kozo Ochi and colleagues (recently reviewed in [106, 108]). Ribosome engineering is a method that uses sub-lethal concentrations of antibiotics that target either the ribosome itself or RNA polymerase (RNAP). Drug-resistant mutants enforced by rifampicin have mutations in $r p o B$ (for the $\beta$-subunit of the RNAP), while those induced by streptomycin carry mutations in rpsL for ribosomal protein $\mathrm{S} 12$ or also in $r s m G$ for 
a 16S rRNA methyltransferase, which gives lower resistance. Combinations of mutations in $r p o B$, rps $L$, or $r s m G$ typically leads to further enhancement of antibiotic production [106, 142, 144]. The ribosome engineering technology proved to be successful in the activation of Act production in $S$. coelicolor and S. lividans, but was also successful in triggering antibiotic production in less wellstudied actinomycetes, such as the production for novel piperidamycins by $S$. mauvecolor triggered by a number of different $r p o B$ or $r p s L$ mutations [56]. The wide application is further demonstrated by the fact that production of the normally silent amino sugar antibiotic 3,3'-neotrehalosadiamine (NTD) by the firmicute Bacillus subtilis was activated by an rpoB mutation [61]. Inducing resistance to several other antibiotics such as gentamicin, erythromycin, and capreomycin also activated antibiotic production, and resistance to these structurally diverse antibiotics typically relates to deletion or expression of an rRNA methyltransferase [63, 80, 134]. A major advantage from the application point of view is that introducing antibiotic resistant mutations can be done by a straightforward selection procedure, rather than by introducing specific mutations, and the technology therefore finds wide application $[2,13,106$, $120,155]$. For further details, we refer to the review by Ochi and colleagues elsewhere in this issue.

\section{Ecological considerations and co-cultivation}

If we are to activate silent antibiotic gene clusters, then understanding of their biological role is of major importance. Streptomycetes grow as a branched multicellular network of hyphae - the vegetative or substrate mycelium-and reproduce through spores that are formed by a specialized aerial mycelium. The onset of development is triggered by stress conditions such as drought or famine. A proportion of the vegetative mycelium lyses following a process of programmed cell death [83], which releases nutrients that presumably form the building blocks for the sporulation process. For a detailed description of the control of morphological differentiation of streptomycetes, we refer to excellent reviews elsewhere [27, 41, 52]. It is likely that the release of nutrients in an otherwise depleted environment attracts competing microbes, and it is logical to perceive the production of antibiotics as a defense mechanism. Indeed, many antibiotics are produced at a time correlating to the onset of development $[16,17,151]$.

A major issue connected to existing strain collections is that they are just that, collections, i.e., the microorganisms have been taken out of their ecological context, and the strains are typically screened individually. Inevitably, in nature, many antibiotics will only be produced after receipt of specific signals, such as from the environment (stress) or from surrounding microbes (symbionts or competitors). Novel molecular ecological methods should aid us in understanding and identifying the triggers that activate the production of antibiotics in nature, which explains the rapidly growing interest in soil and marine ecology related to the production of antibiotics in the natural habitat. The original view that antibiotics are purely antagonistic, acting in nature as they do in the clinic, has recently been questioned [77, 121, 127]. First, the concentrations of antibiotics in the soil are argued to be too low to be efficacious. Second, sub-inhibitory concentrations of antibiotics induce novel phenotypic and genetic responses in exposed organisms, including increased biofilm formation and expression of virulence genes. Thus antibiotics may also act as "collective regulators of the homeostasis of microbial communities", in others words act as signals or cues rather than weapons [77, 121]. Antibiotics acting as signals enable symbiotic relationships between different organisms, each benefiting from either nutrition or protection. The way microbes influence each other has recently been beautifully displayed by Pieter Dorrestein and colleagues, who used imaging mass spectrometry to visualize secondary metabolites and signaling molecules produced by microbes grown in close proximity $[68,158,167]$. The power of this technology is that-in particular with increasing resolutionit may directly identify new chemical elicitors that activate antibiotic production by actinomycetes.

Co-cultivation of different bacterial species was applied successfully to activate the expression of novel antibiotics. The novel antimicrobial alchivemycin A was produced via the co-cultivation of Tsukamurella pulmonis TP-B0596, a mycolic acid-containing bacterium, together with Streptomyces endus S-522. It was proposed that mycolic acid located in the outer cell layer of Tsukamurella induced secondary metabolism in Streptomyces [113]. A competition-based adaptive assay has recently been developed, encouraging the evolution of an organism to produce antimicrobials via serial co-cultivations with a target pathogenic bacterium such as MRSA. Results revealed the activation of the anti-staphylococcal agent holomycin when Streptomyces clavuligerus was co-cultured with MRSA for consecutive passages until significant bioactivity was elicited [26]. While perhaps not feasible in larger screening efforts, such pair-wise interactions may identify important cues and triggers for poorly expressed antibiotics in actinomycetes, which may find wider application.

\section{Chemical elicitors of antibiotic production}

With the promise of finding novel antibiotics, the exploration of elicitors able to activate the expression of silent antibiotic biosynthetic gene clusters has begun, aimed at 
optimal exploitation of the seemingly enormous potential. This section highlights some of the recent advances in this promising line of research.

\section{$N$-acetylglucosamine and the DasR regulon}

A signaling cascade from an extracellular nutrient to the activation of antibiotic production was elucidated in S. coelicolor, which is based on the derepression of the regulon of the GntR-family regulator DasR. Higher concentrations of the cell-wall component $N$-acetylglucosamine (GlcNAc; 5-10 mM) trigger development and antibiotic production under poor growth conditions ("famine"), while they activate development under rich ("feast") conditions (Fig. 2a; [125]). The final receptor of the GlcNAc-derived signal is DasR. GlcNAc is imported via the PEP-dependent phosphotransferase system PTS [102, 103], and subsequently metabolized to glucosamine-6-phosphate (GlcN-6P), an important starter molecule for cell-wall biosynthesis (Fig. 1). GlcN-6P is a ligand for DasR by binding to its effector binding site and thereby reducing the protein's affinity for DNA [124]. This is not unexpected, as GlcN-6P stands at the crossroads of (GlcNAc) $)_{n}$ degradation, GlcNAc transport, and intracellular metabolism, glycolysis, nitrogen and lipid metabolism, as well as peptidoglycan synthesis $[4,84]$, and many genes of these pathways are subject to control by DasR. A complete signaling pathway was established from import of a signal (GlcNAc; first step) to the activation of pathway-specific regulatory genes (actII-ORF4, redZ; final step), see Fig. 1. Interestingly, AtrA appears to counteract DasR, by having opposite actions on the start and end of this signaling pathway. While DasR represses transcription of the genes for the GlcNAc-specific transporter NagE2 (signal import) and for ActII-ORF4 (antibiotic activation), both of these genes are transcriptionally activated by AtrA [103].

The transcription of all known chromosomally encoded antibiotic biosynthetic clusters of $S$. coelicolor (act, cda, $r e d$, and the "cryptic" cpk cluster) is enhanced in dasR mutants [125], while DasR also controls siderophore production [32]. Therefore, manipulating the activity of DasR should potentially allow triggering the expression of antibiotics. Indeed, growth of $S$. coelicolor on minimal media agar plates containing only GlcNAc as the carbon source accelerated development and enhanced antibiotic production, and this was also observed for a number of other actinomycetes [125, 152]. An example is presented in Fig. 2c, which shows the effect of GlcNAc on antibiotic production by six streptomycetes. Interestingly, the $c p k$ cluster for the cryptic type I polyketide synthase $\mathrm{Cpk}$ is also induced by the addition of $N$-acetylglucosamine [125]. This provides one example of novel approaches that may be employed to boost the potential of novel screening procedures. Alternatively, creating mutants in the nag metabolic genes disturbed GlcNAc metabolism in such a way that metabolic intermediates accumulated intracellularly, resulting in increased antibiotic production [141].

It should be noted, however, that GlcNAc and glutamate are also important carbon and nitrogen sources for streptomycetes, and glutamate is preferred over glucose by S. coelicolor $[102,150]$. The fact that GlcNAc and its direct metabolic derivatives promote growth may explain why the compound suppresses antibiotic production in a number of actinomycetes, even though it activates the production in others.

\section{Chemical elicitors that modulate fatty acid biosynthesis}

Besides GlcNAc, other molecules that result from macromolecule recycling should also be considered as elicitors, such as nucleotides from DNA and RNA, oligopeptides and amino acids from proteins, sugars from polysaccharides (including extracellular matrix EPS and LPS) and fatty acids from lipids. Interestingly, a recent screen by Justin Nodwell and colleagues of a chemical library of around 30,000 small molecules for compounds that can act as elicitors of antibiotic production, revealed a family of molecules that act by modulating fatty acid biosynthesis, referred to as antibiotic remodeling compounds (ARCs; [33]), which show similarity to the structure of the furanlike antibiotic triclosan (Fig. 3). Of the ARCs, ARC2 was the most active one. It acts via inhibition of the enoyl-acyl carrier protein reductase FabI, which is a key enzyme of type II fatty acid biosynthesis. Secondary metabolism and fatty acid biosynthesis compete for the common substrate acetyl-CoA, and ARC2 may act via the partial inhibition of FabI, thus allowing a preferential flow of acetyl-CoA to antibiotic production [33, 107].

However, besides interfering with fatty acid metabolism, triclosan is also known to affect quorum sensing and auto-induction mechanisms [38], which mediate cell-cell communication. Quorum sensing-regulated genes were among the most strongly downregulated genes in triclosantreated Pseudomonas aeruginosa cells [28]. In streptomycetes, quorum sensing-like communication is mediated by $\gamma$-butyrolactones, and these play a role in the control of antibiotic production (see next section), and triclosan might also act by interfering with this system.

Extracellular signaling molecules

Microbial, hormone-like, small diffusible molecules known as $\gamma$-butyrolactones play a role in the communication between actinomycetes in the soil, controlling development and antibiotic production (recently reviewed in [57, 133, 161]. The best known example is A-factor (Fig. 3), a 


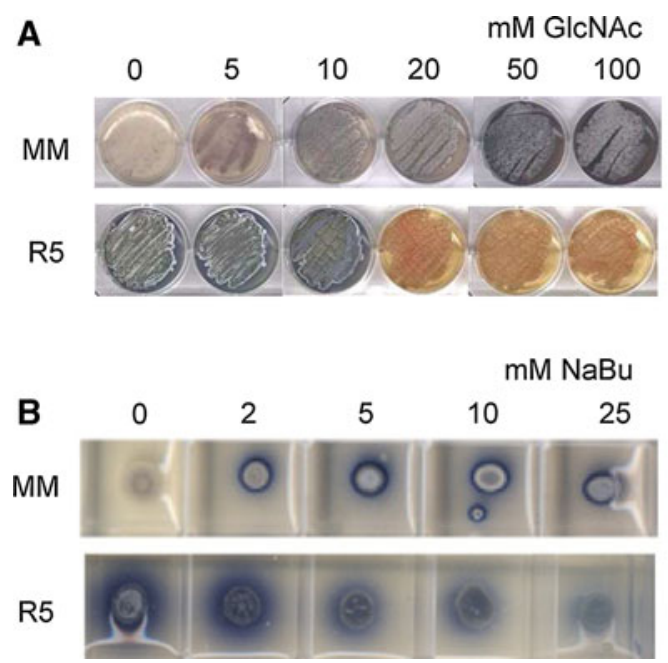

Fig. 2 Medium-dependent activation of antibiotic production by elicitors. Increasing concentrations of GlcNAc (a) or sodium butyrate $(\mathrm{NaBu} ; \mathbf{b})$ repress antibiotic production and development under rich growth conditions (R5 agar plates; "feast") and activate developmental processes in cultures grown under poor conditions (MM agar plates; "famine"). GlcNAc acts by interfering with the activity of DasR, while $\mathrm{NaBu}$ is known to target histone deacetylase (HDAC). The blue pigment is the polyketide antibiotic actinorhodin, spores are

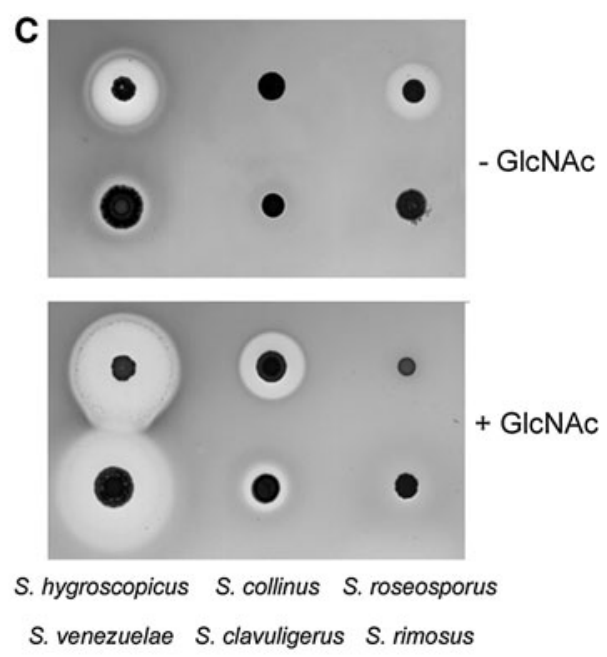

grey-pigmented. $\mathbf{c}$ Effect of GlcNAc on antibiotic production by six selected streptomycetes. The strains were grown on minimal medium agar plates with mannitol $(1 \% \mathrm{w} / \mathrm{v})$ or $N$-acetylglucosamine $(25 \mathrm{mM})$ as the sole carbon source. Bacillus subtilis was used as indicator strain. Halos correspond to antibiotics produced by the streptomycetes. Note that $N$-acetylglucosamine inhibits antibiotic production by $S$. roseosporus. Fig. 2a, c based on [125], Fig. 2b adapted with permission from [96]
Fig. 3 Chemical elicitors of antibiotic production. Chemical structures are presented for known elicitors of antibiotic production and related molecules. For details, we refer to the relevant sections on chemical elicitors in the text<smiles>CC(C)CCCCC(=O)C1C(=O)OC[C@H]1CO</smiles>

A-factor<smiles>CCCc1occ(CO)c1C(=O)O</smiles>

MMF2
PI-factor<smiles>NC(CO)(CO)C(N)(CO)CO</smiles><smiles>O=C(O)CSCC(=O)Nc1ccc(Oc2ccc(OC(F)(F)F)cc2)cc1</smiles><smiles>Oc1ccc(Oc2ccc(Cl)cc2Cl)c(O)c1</smiles><smiles>CC(=O)NC1OC2CC(O)C(O)C(O)C1OC2O</smiles>

$\mathrm{N}$-acetylglucosamine<smiles>CCCC(=O)[O-]</smiles>

Na-butyrate diffusible autoregulatory signaling molecule that controls development and streptomycin production in S. griseus at very low concentrations $[55,110]$. The key enzyme that mediates the biosynthesis of A-factor is the product of the afs $A$ gene product [65]. When A-factor reaches a critical level it binds to the TetR-family regulator ArpA, which consequently dissociates from the $a d p A$ promoter, thereby alleviating its repression. In turn, AdpA then globally trans-activates developmental and antibiotic genes [110]. Antimicrobial regulatory systems that involve $\gamma$-butyrolactones have been discovered in many Streptomyces species, controlling among others the production of Lankacidin and Lankamycin in Streptomyces rochei [165], virginiamycin production in Streptomyces virginiae [66], showdomycin and minimycin in Streptomyces lavendulae [69], auricin production by Streptomyces aureofaciens [104], and the biosynthesis of the type I modular polyketide Cpk in S. coelicolor A3(2) [34]. The activation of many other antibiotics is likely also mediated through $\gamma$-butyrolactones. A second afsA-like gene, $m m f L$, occurs in 
$S$. coelicolor, which is involved in the biosynthesis of methylenomycin furans (MMFs; Fig. 3), controlling a signaling pathway involved in regulation of methylenomycin biosynthesis. Like GBLs, MMFs are synthesized via a butenolide intermediate [31].

Conceivably, $\gamma$-butyrolactones may be applied for drug discovery, as shown by surprising antibiotic stimulation in Streptomyces natalensis by the addition of A-factor from $S$. griseus. S. natalensis produces the autoinducer molecule PI factor (2,3-diamino-2,3-bis (hydroxymethyl)-1,4-butanediol; Fig. 3), which is required for the activation of pimaricin production in this organism [123]. Pimaricin is a 26-membered macrolide tetraene with antifungal activity [7]. Mutants that fail to produce PI factor can not only be restored to produce pimaricin by the addition of PI factor itself, but also by A-factor. While PI factor has a stronger stimulatory effect than A-factor, the cross-complementarity is remarkable. Another example of overlapping signaling routes was found for A-factor and the signaling protein Factor C [19] from Streptomyces flavofungini (originally regarded as a variant of $S$. griseus), although this time it is the lack of A-factor that is complemented. Factor C fully restored normal development and streptomycin production to an A-factor nonproducing strain (AFN) of S. griseus, even though $S$. griseus does not produce Factor $\mathrm{C}$ itself [20]. Factor C restored wild-type levels of A-factor production to the AFN mutant via a yet-unknown mechanism [18], and elucidation of this mechanism should shed new light on the way A-factor production is induced.

Little is yet known about possible application of these signaling molecules as global elicitors of antibiotic production, but considering their activity at very low concentrations this is an interesting approach to follow. Approaches to apply GBLs and MMLs for the activation of antibiotic production were recently proposed by Corre and coworkers [133], and the effect of the furan-like triclosan and the related ARC molecules (previous section) is further support for this conceptual idea.

\section{Rare earth elements}

Rare earth elements (REEs) have recently been implicated as activators of poorly expressed secondary metabolites [106, 108]. Scandium and/or lanthanum enhanced the production of actinomycin, actinorhodin, and streptomycin by two- to as much as 25 -fold at $10-100 \mu \mathrm{M}$ concentrations in Streptomyces antibioticus, S. coelicolor, and S. griseus, respectively. Moreover, scandium also activated actinorhodin in S. lividans [67, 143] and amylase and bacilysin production in $B$. subtilis [60]. REEs are widely distributed and microorganisms respond to their presence in their environment. Addition of REEs, and in particular scandium [106], during screening, may be a useful addition to the array of tools researchers have at their disposal to elicit the production of antibiotics.

\section{HDAC inhibitors}

Another recent addition to the arsenal of chemical elicitors are inhibitors of histone deacetylases or HDACs. Molecules that affect histone acetylation, and thereby change chromatin structure, were shown to activate biosynthetic clusters for natural products in fungi [21, 138]. HDACs antagonize the acetylation of histones in eukaryotes, leading to alterations in chromosome structure and thus affecting gene expression [137]. HDAC proteins are widespread and many are found in bacteria [76], with three HDAC-like genes identified in S. coelicolor [96]. Analysis of the effect of sodium-butyrate, a well-known HDAC inhibitor (Fig. 3), on antibiotic production by $S$. coelicolor showed a major effect on actinorhodin production [96]. Surprisingly, the response of $S$. coelicolor displayed a similar context-dependence as previously observed for $N$-acetylglucosamine [125], namely enhanced production of actinorhodin on minimal media ("famine") and repression under rich ("feast") growth conditions (Fig. 2b; [96]). Whether there is a correlation between the mechanisms by which $\mathrm{N}$-acetylglucosamine and sodium-butyrate enhance antibiotic production awaits further investigation.

\section{Genome mining}

PKS and NRPS gene clusters can be readily identified using bioinformatics, and the natural products they specify can be predicted based on protein domain structures [9, 73]. In recent years, there has been a great expansion in bioinformatics programs enabling the identification of genes involved in secondary metabolite production. This includes ANTIbiotics and Secondary Metabolite Analysis SHell (antiSMASH) [93] and Secondary Metabolite Unknown Regions Finder (SMURF), which facilitate the automated detection of secondary metabolite biosynthesis gene clusters in genome sequence assemblies. Other software packages, such as CLUster SEquence ANalyzer (CLUSEAN), ClustScan, Structure Based Sequence Analysis of Polyketide Synthases (SBSPKS), NRPSPredictor, and Natural Product searcher (NP.searcher), enable the identification of secondary metabolite backbone biosynthesis genes [40]. Other packages include the NORINE database for nonribosomal peptides [23] and BAGEL, which is specific for the identification of biosynthetic clusters for bacteriocins and lantibiotics [35].

The rapid decline in cost made genome sequencing a feasible strategy for identification of gene clusters. Helped by the new software tools that have become available, 
thousands of gene clusters have now been identified, and many more have undoubtedly been elucidated outside the public domain. However, how can we efficiently deal with this wealth of information? Expressing them one by one is like looking for the proverbial needle in a haystack, so how can we identify those clusters that may qualify as producing novel compounds? Following the initial excitement of the massive amount of new cluster data, we should not just focus on identifying homologs of known biosynthetic gene clusters. Instead, we should make use of computational techniques to intelligently sieve through the data for interesting new biochemistry. For example, all gene clusters may be subdivided into families using an evolutionary distance metric (Cimermancic, Medema, Fischbach et al., unpublished data). This allows one to focus on families without gene clusters encoding the biosynthesis of known compounds. Alternatively, one could focus on families that contain gene clusters with entirely novel combinations of homologs of well-known enzymes. Such gene clusters are likely associated with specific types of regulatory genes and/or regulatory elements, as well as genes for modifying enzymes and transporters. Genomic, transcriptomic, and/or proteomic data may be used as further support, e.g., to select those clusters that appear poorly expressed under routine growth conditions. Here we look at cis-acting elements and specific regulatory genes that may act as socalled "molecular beacons" [11], which may point scientists in the right direction in their search for novel antibiotic biosynthetic gene clusters.

\section{Regulatory elements as beacons}

In terms of scanning the genomes of yet un(der)explored streptomycetes, following the distribution of regulatory elements for global antibiotic regulators may be a useful strategy. As an example, scanning the $S$. coelicolor genome using the PREDetector algorithm [49] revealed some 200 sequences that conformed to the consensus binding site for DasR (dre, for DasR responsive element), namely the palindromic 16-bp consensus sequence A(G/C)TGGTCTA $\operatorname{GACCA}(\mathrm{G} / \mathrm{C}) \mathrm{T}$. The DasR regulatory network is well conserved in streptomycetes, with around $75 \%$ of the DasR-binding (dre) sites predicted in S. coelicolor also found upstream of the orthologous genes in $S$. avermitilis (Rigali, Titgemeyer and van Wezel, unpublished data and [153]). Scanning genome sequences in the databases suggested that DasR may control the biosynthesis of novel antibiotics as well as important clinical drugs, including clavulanic acid, chloramphenicol, daptomycin, and teicoplanin.

A similar approach could be followed by analyzing the distribution of the regulatory element of AtrA, which among others controls actinorhodin production in
S. coelicolor [148]. AtrA recognizes the consensus sequence cGGAA(T/C)(G/C)NNN(C/G)(A/G)TTCCg (are, for AtrA-responsive element) and likely qualifies as a global regulator (K.J. McDowall, pers. comm.). AtrA occurs in all streptomycetes, its DNA binding domain is extremely well conserved ( $>90 \%$ aa identity), and an AtrA orthologue activates streptomycin production in S. griseus [50]. Following a similar approach to the DasR regulatory network should reveal how the AtrA network associates with (novel) secondary metabolite gene clusters. The same is true for other regulatory networks.

Regulatory genes as beacons

\section{mbtH-family genes and NRPS}

The gene $m b t H$ was identified in Mycobacterium tuberculosis within the NRPS gene cluster for mycobactin, a peptide siderophore. The $m b t H$-like genes are widespread in Streptomyces genomes, and some of the gene products stimulate adenylation reactions by tightly binding to NRPS proteins containing adenylation (A) domains. Their expression may be important for the efficient production of native and recombinant secondary metabolites produced using NRPS enzymes [11]. As an example, $v b s G$, an $m b t H$ homolog in Rhizobium leguminosarum, is required for the production of the cyclic, trihydroxamate siderophore vicibactin [24]. Thus, $m b t H$ homologs can be useful for identification of specific types of NRPS gene clusters [11].

mmyB-family regulatory genes

The $m m y B$-like genes are also candidates as beacons for antibiotic biosynthetic gene clusters. $m m y B$ itself is a transcriptional regulatory gene involved in the biosynthesis of methylenomycin in S. coelicolor [105]. The crystal structure of the MmyB-family regulator MltR from Chloroflexus aurantiacus was resolved; the proteins consist of an Xre-type N-terminal DNA-binding domain and a C-terminal ligand-binding module that is related to the PerArnt-Sim (PAS) domain, and these regulators most likely bind complex fatty acid molecules as ligands that activate their DNA binding activity [163]. Many $m m y B$-family regulatory genes lie divergently transcribed from, and share the promoter region with, genes related to antibiotic production. There are eight in total in S. coelicolor, including $m m y B$ itself, which controls Mmy biosynthesis and SCO6925, which lies next to a lantibiotic biosynthetic cluster. The other genes are adjacent to a gene for an NAD(P)H-dependent short- or medium-chain dehydrogenases/reductase (SDR or MDR), a diverse family with alcohol dehydrogenase as the best known example [64]. This suggestive linkage is conserved in actinomycetes, 


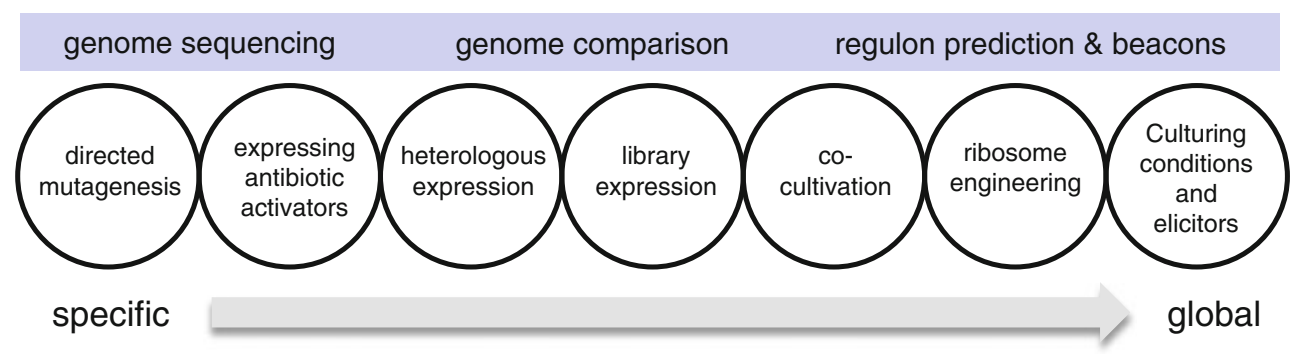

Fig. 4 Approaches to activate antibiotic production. Summary of methods applied to increase or induce the production of secondary metabolites. From left to right, technologies are presented with increasing applicability at higher throughput, from strain-specific

suggesting that the genetic association with antibioticrelated genes appears to be widespread.

The $m m y B$-family gene SCO4944 is conserved in streptomycetes and other actinomycetes, and may therefore be seen as the main member of the family in actinomycetes. Phylogenetic evidence suggests that SCO4944 may control SCO4945, a gene for a mycothiol-dependent formaldehyde dehydrogenase. Surprisingly, the orthologs in S. griseus, SGR_6891 and SGR_6892, respectively, are separated by one gene from afsA (SGR_6889) for A-factor synthase, and their transcription is induced by A-factor immediately after its addition to liquid-grown cultures [48], suggesting that both genes are part of A-factor regulatory cascade. Suggestively, MmyB binds furans as ligands, which are structurally similar to A-factor.

Thus, $m m y B$ homologs may form a very useful tool as genetic beacon for the identification of antibiotic-related genes in actinomycete genomes, and that searching for large gene clusters with suggestive genes such as modifying enzymes and transporters could be a fruitful strategy for finding new candidate antibiotic biosynthetic clusters.

\section{Final considerations}

With next-generation sequencing technologies and the increasing understanding of antibiotic regulation, new strategies for "awakening" poorly expressed antibiotics are becoming available. A combination of different regulatory approaches should be considered for activating antibiotic production, such as the application of elicitor molecules or transcription stimulation, to enhance the expression of novel biosynthetic gene clusters. Important approaches to explore also lie in the direction of culture conditions. The different methods range from strain-specific to globally applicable (Fig. 4). One obvious problem with routine screening methods is the absence of the natural competitors and symbionts that are found in the natural habitat. Cocultivation methods or chemical mimicking of inter-species (directed mutants, expression of activators) to HT screening using elicitors. Genome mining approaches range from single genome sequencing and annotation (left) to global genome comparison (right). For details on the technologies, see the text

communication are promising new approaches in the search for novel antibiotics. One aspect that has obtained surprisingly little attention is that while most scientists search for novel antibiotics, the problem lies not so much in the lack of antibiotics, but in the widespread resistance that limits their application. The success story of clavulanic acid as inhibitor of $\beta$-lactamases $[114,122]$ perfectly illustrates the potential of such approaches. Therefore, targeting antibiotic resistance should offer a very attractive alternative to antibiotic discovery. We anticipate that similar considerations as those described above for antibiotics will also be applicable to the activation of natural products involved in counteracting antibiotic resistance mechanisms.

Acknowledgments We are grateful to Young Choi for drawing chemical structures, to Geneviève Girard for comments on the manuscript, and to Kenneth McDowall, Marnix Medema and Michael Fischbach for sharing unpublished data. The work was supported by a CSC PhD fellowship from the Chinese government to HZ and by grant 10467 from the Netherlands Technology Foundation STW to GPvW.

\section{References}

1. Aharonowitz Y (1980) Nitrogen metabolite regulation of antibiotic biosynthesis. Annu Rev Microbiol 34:209-233

2. Alexander DC, Rock J, He X, Brian P, Miao V, Baltz RH (2010) Development of a genetic system for combinatorial biosynthesis of lipopeptides in Streptomyces fradiae and heterologous expression of the A54145 biosynthesis gene cluster. Appl Environ Microbiol 76:6877-6887

3. Allenby NE, Laing E, Bucca G, Kierzek AM, Smith CP (2012) Diverse control of metabolism and other cellular processes in Streptomyces coelicolor by the PhoP transcription factor: genome-wide identification of in vivo targets. Nucleic acids Res 40:9543-9556

4. Altermann E, Klaenhammer TR (2005) PathwayVoyager: pathway mapping using the Kyoto Encyclopedia of Genes and Genomes (KEGG) database. BMC genomics 6:60

5. Angell S, Lewis CG, Buttner MJ, Bibb MJ (1994) Glucose repression in Streptomyces coelicolor A3(2): a likely regulatory role for glucose kinase. Mol Gen Genet 244:135-143 
6. Angell S, Schwarz E, Bibb MJ (1992) The glucose kinase gene of Streptomyces coelicolor A3(2): its nucleotide sequence, transcriptional analysis and role in glucose repression. Mol Microbiol 6:2833-2844

7. Aparicio JF, Colina AJ, Ceballos E, Martin JF (1999) The biosynthetic gene cluster for the 26-membered ring polyene macrolide pimaricin. A new polyketide synthase organization encoded by two subclusters separated by functionalization genes. J Biol Chem 274:10133-10139

8. Arias CA, Murray BE (2009) Antibiotic-resistant bugs in the 21st century-a clinical super-challenge. $\mathrm{N}$ Engl J Med 360:439-443

9. Bachmann BO, Ravel J (2009) Chapter 8. Methods for in silico prediction of microbial polyketide and nonribosomal peptide biosynthetic pathways from DNA sequence data. Methods Enzymol 458:181-217

10. Baltz RH (2007) Antimicrobials from actinomycetes: back to the future. Microbe 2:125-131

11. Baltz RH (2011) Function of MbtH homologs in nonribosomal peptide biosynthesis and applications in secondary metabolite discovery. J Ind Microbiol Biotechnol 38:1747-1760

12. Baltz RH (2008) Renaissance in antibacterial discovery from actinomycetes. Current Opin Pharmacol 8:557-563

13. Beltrametti F, Rossi R, Selva E, Marinelli F (2006) Antibiotic production improvement in the rare actinomycete Planobispora rosea by selection of mutants resistant to the aminoglycosides streptomycin and gentamycin and to rifamycin. J Ind Microbiol Biotechnol 33:283-288

14. Bentley SD, Chater KF, Cerdeno-Tarraga AM, Challis GL, Thomson NR, James KD, Harris DE, Quail MA, Kieser H, Harper D, Bateman A, Brown S, Chandra G, Chen CW, Collins M, Cronin A, Fraser A, Goble A, Hidalgo J, Hornsby T, Howarth S, Huang CH, Kieser T, Larke L, Murphy L, Oliver K, O'Neil S, Rabbinowitsch E, Rajandream MA, Rutherford K, Rutter S, Seeger K, Saunders D, Sharp S, Squares R, Squares S, Taylor K, Warren T, Wietzorrek A, Woodward J, Barrell BG, Parkhill J, Hopwood DA (2002) Complete genome sequence of the model actinomycete Streptomyces coelicolor A3(2). Nature 417:141-147

15. Bérdy J (2005) Bioactive microbial metabolites. J Antibiot (Tokyo) 58:1-26

16. Bibb MJ (2005) Regulation of secondary metabolism in streptomycetes. Curr Opin Microbiol 8:208-215

17. Bibb MJ, Hesketh A (2009) Chapter 4. Analyzing the regulation of antibiotic production in streptomycetes. Methods Enzymol 458:93-116

18. Birko Z, Bialek S, Buzas K, Szajli E, Traag BA, Medzihradszky KF, Rigali S, Vijgenboom E, Penyige A, Kele Z, van Wezel GP, Biro S (2007) The secreted signaling protein factor $C$ triggers the A-factor response regulon in Streptomyces griseus: overlapping signaling routes. Mol Cell Proteomics 6:1248-1256

19. Biro S, Bekesi I, Vitalis S, Szabo G (1980) A substance effecting differentiation in Streptomyces griseus. Purification and properties. Eur J Biochem 103:359-363

20. Biro S, Birko Z, van Wezel GP (2000) Transcriptional and functional analysis of the gene for factor $C$, an extracellular signal protein involved in cytodifferentiation of Streptomyces griseus. Antonie Van Leeuwenhoek 78:277-285

21. Bok JW, Chiang YM, Szewczyk E, Reyes-Dominguez Y, Davidson AD, Sanchez JF, Lo HC, Watanabe K, Strauss J, Oakley BR, Wang CC, Keller NP (2009) Chromatin-level regulation of biosynthetic gene clusters. Nat Chem Biol 5:462-464

22. Brückner R, Titgemeyer F (2002) Carbon catabolite repression in bacteria: choice of the carbon source and autoregulatory limitation of sugar utilization. FEMS Microbiol Lett 209:141148
23. Caboche S, Pupin M, Leclere V, Fontaine A, Jacques P, Kucherov G (2008) NORINE: a database of nonribosomal peptides. Nucleic Acids Res 36:D326-D331

24. Carter RA, Worsley PS, Sawers G, Challis GL, Dilworth MJ, Carson KC, Lawrence JA, Wexler M, Johnston AW, Yeoman $\mathrm{KH}$ (2002) The $v b s$ genes that direct synthesis of the siderophore vicibactin in Rhizobium leguminosarum: their expression in other genera requires ECF sigma factor RpoI. Mol Microbiol 44:1153-1166

25. Challis GL, Hopwood DA (2003) Synergy and contingency as driving forces for the evolution of multiple secondary metabolite production by Streptomyces species. Proc Natl Acad Sci USA 100:14555-14561

26. Charusanti P, Fong NL, Nagarajan H, Pereira AR, Li HJ, Abate EA, Su Y, Gerwick WH, Palsson BO (2012) Exploiting adaptive laboratory evolution of Streptomyces clavuligerus for antibiotic discovery and overproduction. PLoS One 7:e33727

27. Chater KF (2006) Streptomyces inside-out: a new perspective on the bacteria that provide us with antibiotics. Philosophical Transactions of the Royal Society of London. Ser B Biol Sci 361:761-768

28. Chuanchuen R, Schweizer HP (2012) Global transcriptional responses to triclosan exposure in Pseudomonas aeruginosa. Int J Antimicrob Agents 40:114-122

29. Colson S, Stephan J, Hertrich T, Saito A, van Wezel GP, Titgemeyer F, Rigali S (2007) Conserved cis-acting elements upstream of genes composing the chitinolytic system of streptomycetes are DasR-responsive elements. J Mol Microbiol Biotechnol 12:60-66

30. Colson S, van Wezel GP, Craig M, Noens EE, Nothaft H, Mommaas AM, Titgemeyer F, Joris B, Rigali S (2008) The chitobiose-binding protein, DasA, acts as a link between chitin utilization and morphogenesis in Streptomyces coelicolor. Microbiology 154:373-382

31. Corre C, Song L, O'Rourke S, Chater KF, Challis GL (2008) 2-Alkyl-4-hydroxymethylfuran-3-carboxylic acids, antibiotic production inducers discovered by Streptomyces coelicolor genome mining. Proc Natl Acad Sci USA 105:17510-17515

32. Craig M, Lambert S, Jourdan S, Tenconi E, Colson S, Maciejewska M, Martin JF, Ongena M, van Wezel G, Rigali S (2012) Unsuspected control of siderophore production by $N$-acetylglucosamine in streptomycetes. Environ Microbiol Rep 4:512-521

33. Craney A, Ozimok C, Pimentel-Elardo SM, Capretta A, Nodwell JR (2012) Chemical perturbation of secondary metabolism demonstrates important links to primary metabolism. Chem Biol 19:1020-1027

34. D'Alia D, Eggle D, Nieselt K, Hu WS, Breitling R, Takano E (2011) Deletion of the signalling molecule synthase ScbA has pleiotropic effects on secondary metabolite biosynthesis, morphological differentiation and primary metabolism in Streptomyces coelicolor A3(2). Microb Biotechnol 4:239-251

35. de Jong A, van Heel AJ, Kok J, Kuipers OP (2010) BAGEL2: mining for bacteriocins in genomic data. Nucleic Acids Res 38:W647-W651

36. Demain AL (1989) Carbon source regulation of idiolite biosynthesis in regulation of secondary metabolism in actinomycetes. CRC Press, Boca Raton, pp 127-134

37. Demain AL (1999) Pharmaceutically active secondary metabolites of microorganisms. Appl Microbiol Biotechnol 52:455-463

38. Dobretsov S, Dahms HU, Yili H, Wahl M, Qian PY (2007) The effect of quorum-sensing blockers on the formation of marine microbial communities and larval attachment. FEMS Microbiol Ecol 60:177-188

39. Dulaney EL (1948) Observations on Streptomyces griseus: II. Nitrogen sources for growth and streptomycin production. J Bacteriol 56:305-313 
40. Fedorova D, Moktali V, Medema H (2012) Bioinformatics approaches and software for detection of secondary metabolic gene clusters. In: Keller NP, Turner G (eds) Fungal secondary metabolism, vol. 944. Humana Press, New York, pp 23-45

41. Flärdh K, Buttner MJ (2009) Streptomyces morphogenetics: dissecting differentiation in a filamentous bacterium. Nat Rev Microbiol 7:36-49

42. Fleming A (1929) The antibacterial action of a Penicillium, with special reference to their use for the isolation of $B$. influenzae. Brit J Exp Pathol 10:226-236

43. Floriano B, Bibb M (1996) afsR is a pleiotropic but conditionally required regulatory gene for antibiotic production in Streptomyces coelicolor A3(2). Mol Microbiol 21:385-396

44. Goosen N, van de Putte P (1995) The regulation of transcription initiation by integration host factor. Mol Microbiol 16:1-7

45. Görke B, Stülke J (2008) Carbon catabolite repression in bacteria: many ways to make the most out of nutrients. Nat Rev Microbiol 6:613-624

46. Gross H (2009) Genomic mining-a concept for the discovery of new bioactive natural products. Curr Opin Drug Discov Dev 12:207-219

47. Gubbens J, Janus M, Florea BI, Overkleeft HS, van Wezel GP (2012) Identification of glucose kinase dependent and independent pathways for carbon control of primary metabolism, development and antibiotic production in Streptomyces coelicolor by quantitative proteomics. Mol Microbiol 86:1490-1507

48. Hara H, Ohnishi Y, Horinouchi S (2009) DNA microarray analysis of global gene regulation by A-factor in Streptomyces griseus. Microbiology 155:2197-2210

49. Hiard S, Maree R, Colson S, Hoskisson PA, Titgemeyer F, van Wezel GP, Joris B, Wehenkel L, Rigali S (2007) PREDetector: a new tool to identify regulatory elements in bacterial genomes. Biochem Biophys Res Commun 357:861-864

50. Hirano S, Tanaka K, Ohnishi Y, Horinouchi S (2008) Conditionally positive effect of the TetR-family transcriptional regulator AtrA on streptomycin production by Streptomyces griseus. Microbiology 154:905-914

51. Hopwood DA (1999) Forty years of genetics with Streptomyces: from in vivo through in vitro to in silico. Microbiology 145:2183-2202

52. Hopwood DA (2006) Soil to genomics: the Streptomyces chromosome. Annu Rev Genet 40:1-23

53. Hopwood DA (2007) Streptomyces in nature and medicine: the antibiotic makers. Oxford University Press, New York

54. Horinouchi S, Beppu T (1992) Autoregulatory factors and communication in actinomycetes. Annu Rev Microbiol 46:377398

55. Horinouchi S, Beppu T (1994) A-factor as a microbial hormone that controls cellular differentiation and secondary metabolism in Streptomyces griseus. Mol Microbiol 12:859-864

56. Hosaka T, Ohnishi-Kameyama M, Muramatsu H, Murakami K, Tsurumi Y, Kodani S, Yoshida M, Fujie A, Ochi K (2009) Antibacterial discovery in actinomycetes strains with mutations in RNA polymerase or ribosomal protein S12. Nat Biotechnol 27:462-464

57. Hsiao NH, Gottelt M, Takano E (2009) Chapter 6. Regulation of antibiotic production by bacterial hormones. Methods Enzymol 458:143-157

58. Huang J, Shi J, Molle V, Sohlberg B, Weaver D, Bibb MJ, Karoonuthaisiri N, Lih C-J, Kao CM, Buttner MJ, Cohen SJ (2005) Cross regulation among disparate antibiotic biosynthetic pathways of Streptomyces coelicolor. Mol Microbiol 58:12761287

59. Ikeda H, Ishikawa J, Hanamoto A, Shinose M, Kikuchi H, Shiba T, Sakaki Y, Hattori M, Omura S (2003) Complete genome sequence and comparative analysis of the industrial microorganism Streptomyces avermitilis. Nat Biotechnol 21:526-531

60. Inaoka T, Ochi K (2011) Scandium stimulates the production of amylase and bacilysin in Bacillus subtilis. Appl Environ Microbiol 77:8181-8183

61. Inaoka T, Takahashi K, Yada H, Yoshida M, Ochi K (2004) RNA polymerase mutation activates the production of a dormant antibiotic 3,3'-neotrehalosadiamine via an autoinduction mechanism in Bacillus subtilis. J Biol Chem 279:3885-3892

62. Iqbal M, Mast Y, Amin R, Hodgson DA, Wohlleben W, Burroughs NJ (2012) Extracting regulator activity profiles by integration of de novo motifs and expression data: characterizing key regulators of nutrient depletion responses in Streptomyces coelicolor. Nucleic Acids Res 40:5227-5239

63. Johansen SK, Maus CE, Plikaytis BB, Douthwaite S (2006) Capreomycin binds across the ribosomal subunit interface using tlyA-encoded $2^{\prime}-O$-methylations in $16 \mathrm{~S}$ and $23 \mathrm{~S}$ rRNAs. Mol Cell 23:173-182

64. Jornvall H, Hedlund J, Bergman T, Oppermann U, Persson B (2010) Superfamilies SDR and MDR: from early ancestry to present forms. Emergence of three lines, a Zn-metalloenzyme, and distinct variabilities. Biochem Biophys Res Commun 396:125-130

65. Kato JY, Funa N, Watanabe H, Ohnishi Y, Horinouchi S (2007) Biosynthesis of gamma-butyrolactone autoregulators that switch on secondary metabolism and morphological development in Streptomyces. Proc Natl Acad Sci USA 104:2378-2383

66. Kawachi R, Akashi T, Kamitani Y, Sy A, Wangchaisoonthorn U, Nihira T, Yamada Y (2000) Identification of an AfsA homologue (BarX) from Streptomyces virginiae as a pleiotropic regulator controlling autoregulator biosynthesis, virginiamycin biosynthesis and virginiamycin M1 resistance. Mol Microbiol 36:302-313

67. Kawai K, Wang G, Okamoto S, Ochi K (2007) The rare earth, scandium, causes antibiotic overproduction in Streptomyces spp. FEMS Microbiol Lett 274:311-315

68. Kersten RD, Yang YL, Xu Y, Cimermancic P, Nam SJ, Fenical W, Fischbach MA, Moore BS, Dorrestein PC (2011) A mass spectrometry-guided genome mining approach for natural product peptidogenomics. Nat Chem Biol 7:794-802

69. Kitani S, Yamada Y, Nihira T (2001) Gene replacement analysis of the butyrolactone autoregulator receptor (FarA) reveals that FarA acts as a novel regulator in secondary metabolism of Streptomyces lavendulae FRI-5. J Bacteriol 183:4357-4363

70. Klevens RM, Morrison MA, Nadle J, Petit S, Gershman K, Ray S, Harrison LH, Lynfield R, Dumyati G, Townes JM, Craig AS, Zell ER, Fosheim GE, McDougal LK, Carey RB, Fridkin SK (2007) Invasive methicillin-resistant Staphylococcus aureus infections in the United States. JAMA J Am Med Assoc 298:1763-1771

71. Lahana R (1999) How many leads from HTS? Drug Discov Today 4:447-448

72. Laureti L, Song L, Huang S, Corre C, Leblond P, Challis GL, Aigle B (2011) Identification of a bioactive 51-membered macrolide complex by activation of a silent polyketide synthase in Streptomyces ambofaciens. Proc Natl Acad Sci USA 108:6258-6263

73. Lautru S, Challis GL (2004) Substrate recognition by nonribosomal peptide synthetase multi-enzymes. Microbiology 150:1629-1636

74. Lee J, Hwang Y, Kim S, Kim E, Choi C (2000) Effect of a global regulatory gene, afsR2, from Streptomyces lividans on avermectin production in Streptomyces avermitilis. J Biosci Bioeng 89:606-608

75. Lee PC, Umeyama T, Horinouchi S (2002) afs $S$ is a target of AfsR, a transcriptional factor with ATPase activity that globally 
controls secondary metabolism in Streptomyces coelicolor A3(2). Mol Microbiol 43:1413-1430

76. Leipe DD, Landsman D (1997) Histone deacetylases, acetoin utilization proteins and acetylpolyamine amidohydrolases are members of an ancient protein superfamily. Nucleic Acids Res 25:3693-3697

77. Linares JF, Gustafsson I, Baquero F, Martinez JL (2006) Antibiotics as intermicrobial signaling agents instead of weapons. Proc Natl Acad Sci USA 103:19484-19489

78. Lipinski CA, Lombardo F, Dominy BW, Feeney PJ (2001) Experimental and computational approaches to estimate solubility and permeability in drug discovery and development settings. Adv Drug Deliv Rev 46:3-26

79. Liu G, Chater KF, Chandra G, Niu G, Tan H (2013) Molecular regulation of antibiotic biosynthesis in Streptomyces. Microbiol Mol Biol Rev 77:112-143

80. Liu M, Kirpekar F, Van Wezel GP, Douthwaite S (2000) The tylosin resistance gene triB of Streptomyces fradiae encodes a methyltransferase that targets G748 in 23S rRNA. Mol Microbiol 37:811-820

81. Maharjan S, Oh TJ, Lee HC, Sohng JK (2009) Identification and functional characterization of an $a f s R$ homolog regulatory gene from Streptomyces venezuelae ATCC 15439. J Microbiol Biotechnol 19:121-127

82. Malpartida F, Hopwood DA (1986) Physical and genetic characterisation of the gene cluster for the antibiotic actinorhodin in Streptomyces coelicolor A3(2). Mol Gen Genet 205:66-73

83. Manteca A, Fernandez M, Sanchez J (2005) A death round affecting a young compartmentalized mycelium precedes aerial mycelium dismantling in confluent surface cultures of Streptomyces antibioticus. Microbiology 151:3689-3697

84. Mao X, Cai T, Olyarchuk JG, Wei L (2005) Automated genome annotation and pathway identification using the KEGG Orthology (KO) as a controlled vocabulary. Bioinformatics 21:37873793

85. Martín JF (2004) Phosphate control of the biosynthesis of antibiotics and other secondary metabolites is mediated by the PhoRPhoP system: an unfinished story. J Bacteriol 186:5197-5201

86. Martín JF, Demain A (1980) Control of antibiotic biosynthesis. Microbiol Rev 44:230-251

87. Martin JF, Aparicio JF (2009) Enzymology of the polyenes pimaricin and candicidin biosynthesis. Methods Enzymol 459:215-242

88. Martin JF, Liras P (2010) Engineering of regulatory cascades and networks controlling antibiotic biosynthesis in Streptomyces. Curr Opin Microbiol 13:263-273

89. Martin JF, Sola-Landa A, Santos-Beneit F, Fernandez-Martinez LT, Prieto C, Rodriguez-Garcia A (2011) Cross-talk of global nutritional regulators in the control of primary and secondary metabolism in Streptomyces. Microb Biotechnol 4:165-174

90. Martinez A, Kolvek SJ, Hopke J, Yip CL, Osburne MS (2005) Environmental DNA fragment conferring early and increased sporulation and antibiotic production in Streptomyces species. Appl Environ Microbiol 71:1638-1641

91. Matsumoto A, Ishizuka H, Beppu T, Horinouchi S (1995) Involvement of a small ORF downstream of the $a f s R$ gene in the regulation of secondary metabolism in Streptomyces coelicolor A3(2). Actinomycetologica 9:37-43

92. McDowall KJ, Thamchaipenet A, Hunter IS (1999) Phosphate control of oxytetracycline production by Streptomyces rimosus is at the level of transcription from promoters overlapped by tandem repeats similar to those of the DNA-binding sites of the OmpR family. J Bacteriol 181:3025-3032

93. Medema M, Blin K, Cimermancic P, de Jager V, Zakrzewski P, Fischbach MA, Weber T, Takano E, Breitling R (2011) anti-
SMASH: rapid identification, annotation and analysis of secondary metabolite biosynthesis gene clusters in bacterial and fungal genome sequences. Nucleic Acids Res 39:W339-W346

94. Medema MH, Breitling R, Bovenberg R, Takano E (2011) Exploiting plug-and-play synthetic biology for drug discovery and production in microorganisms. Nat Rev Microbiol 9:131-137

95. Mendes MV, Tunca S, Anton N, Recio E, Sola-Landa A, Aparicio JF, Martin JF (2007) The two-component phoR-phoP system of Streptomyces natalensis: inactivation or deletion of phoP reduces the negative phosphate regulation of pimaricin biosynthesis. Metab Eng 9:217-227

96. Moore JM, Bradshaw E, Seipke RF, Hutchings MI, McArthur M (2012) Use and discovery of chemical elicitors that stimulate biosynthetic gene clusters in Streptomyces bacteria. Methods Enzymol 517:367-385

97. Myers PL (1997) Will combinatorial chemistry deliver real medicines? Curr Opin Biotechnol 8:701-707

98. Nazari B, Kobayashi M, Saito A, Hassaninasab A, Miyashita K, Fujii T (2012) Chitin-induced gene expression involved in secondary metabolic pathways in Streptomyces coelicolor A3(2) grown in soil. Appl Environ Microbiol 79:707-713

99. Nett M, Ikeda H, Moore BS (2009) Genomic basis for natural product biosynthetic diversity in the actinomycetes. Nat Prod Rep 26:1362-1384

100. Newman DJ, Cragg GM (2007) Natural products as sources of new drugs over the last 25 years. J Nat Prod 70:461-477

101. Nodwell JR, Losick R (1998) Purification of an extracellular signaling molecule involved in production of the aerial mycelium by Streptomyces coelicolor. J Bacteriol 180:1334-1337

102. Nothaft H, Dresel D, Willimek A, Mahr K, Niederweis M, Titgemeyer F (2003) The phosphotransferase system of Streptomyces coelicolor is biased for $\mathrm{N}$-acetylglucosamine metabolism. J Bacteriol 185:7019-7023

103. Nothaft H, Rigali S, Boomsma B, Swiatek M, McDowall KJ, van Wezel GP, Titgemeyer F (2010) The permease gene nagE2 is the key to $N$-acetylglucosamine sensing and utilization in Streptomyces coelicolor and is subject to multi-level control. Mol Microbiol 75:1133-1144

104. Novakova R, Rehakova A, Kutas P, Feckova L, Kormanec J (2011) The role of two SARP family transcriptional regulators in regulation of the auricin gene cluster in Streptomyces aureofaciens CCM 3239. Microbiology 157:1629-1639

105. O'Rourke S, Wietzorrek A, Fowler K, Corre C, Challis GL, Chater KF (2009) Extracellular signalling, translational control, two repressors and an activator all contribute to the regulation of methylenomycin production in Streptomyces coelicolor. Mol Microbiol 71:763-778

106. Ochi K, Hosaka T (2013) New strategies for drug discovery: activation of silent or weakly expressed microbial gene clusters. Appl Microbiol Biotechnol 97:87-98

107. Ochi K, Okamoto S (2012) A magic bullet for antibiotic discovery. Chem Biol 19:932-934

108. Ochi K, Tanaka Y, Tojo S (2013) Activating the expression of bacterial cryptic genes by rроB mutations in RNA polymerase or by rare earth elements. J Ind Microbiol Biotechnol (submitted)

109. Ohnishi Y, Ishikawa J, Hara H, Suzuki H, Ikenoya M, Ikeda H, Yamashita A, Hattori M, Horinouchi S (2008) Genome sequence of the streptomycin-producing microorganism Streptomyces griseus IFO 13350. J Bacteriol 190:4050-4060

110. Ohnishi Y, Kameyama S, Onaka H, Horinouchi S (1999) The A-factor regulatory cascade leading to streptomycin biosynthesis in Streptomyces griseus: identification of a target gene of the A-factor receptor. Mol Microbiol 34:102-111 
111. Oliynyk M, Samborskyy M, Lester JB, Mironenko T, Scott N, Dickens S, Haydock SF, Leadlay PF (2007) Complete genome sequence of the erythromycin-producing bacterium Saccharopolyspora erythraea NRRL23338. Nat Biotechnol 25:447-453

112. Omura S, Ikeda $\mathrm{H}$, Ishikawa J, Hanamoto A, Takahashi C, Shinose M, Takahashi Y, Horikawa H, Nakazawa H, Osonoe T, Kikuchi H, Shiba T, Sakaki Y, Hattori M (2001) Genome sequence of an industrial microorganism Streptomyces avermitilis: deducing the ability of producing secondary metabolites. Proc Natl Acad Sci USA 98:12215-12220

113. Onaka H, Mori Y, Igarashi Y (2011) Mycolic acid-containing bacteria induce natural-product biosynthesis in Streptomyces species. Appl Environ Microbiol 77:400-406

114. Paradkar A (2013) Clavulanic acid production by Streptomyces clavuligerus: biogenesis, regulation and strain improvement. J Antibiot. doi:10.1038/ja.2013.26

115. Parajuli N, Viet HT, Ishida K, Tong HT, Lee HC, Liou K, Sohng JK (2005) Identification and characterization of the $a s_{s} R$ homologue regulatory gene from Streptomyces peucetius ATCC 27952. Res Microbiol 156:707-712

116. Pawlik K, Kotowska M, Chater KF, Kuczek K, Takano E (2007) A cryptic type I polyketide synthase $(c p k)$ gene cluster in Streptomyces coelicolor A3(2). Arch Microbiol 187:87-99

117. Payne DJ, Gwynn MN, Holmes DJ, Pompliano DL (2007) Drugs for bad bugs: confronting the challenges of antibacterial discovery. Nat Rev Drug Discov 6:29-40

118. Piepersberg W, Distler J (1997) Aminoglycosides and sugar components in other secondary metabolites. In: Rehm HJ, Reed $\mathrm{G}$ (eds) Products of secondary metabolism, vol. 7, 2nd edn. VCH-Verlagsgesellschaft, Weinheim, pp 397-488

119. Pimm SL, Russell GJ, Gittleman JL, Brooks TM (1995) The future of biodiversity. Science 269:347-350

120. Qiu X, Yan X, Liu M, Han R (2012) Genetic and proteomic characterization of rpoB mutations and their effect on nematicidal activity in Photorhabdus luminescens LN2. PLoS One 7:e43114

121. Ratcliff WC, Denison RF (2011) Microbiology. Alternative actions for antibiotics. Science 332:547-548

122. Reading C, Cole M (1977) Clavulanic acid: a beta-lactamaseinhibiting beta-lactam from Streptomyces clavuligerus. Antimicrob Agents Chemother 11:852-857

123. Recio E, Colinas A, Rumbero A, Aparicio JF, Martín JF (2004) PI factor, a novel type quorum-sensing inducer elicits pimaricin production in Streptomyces natalensis. J Biol Chem 279:4158641593

124. Rigali S, Nothaft H, Noens EE, Schlicht M, Colson S, Muller M, Joris B, Koerten HK, Hopwood DA, Titgemeyer F, van Wezel GP (2006) The sugar phosphotransferase system of Streptomyces coelicolor is regulated by the GntR-family regulator DasR and links $N$-acetylglucosamine metabolism to the control of development. Mol Microbiol 61:1237-1251

125. Rigali S, Titgemeyer F, Barends S, Mulder S, Thomae AW, Hopwood DA, van Wezel GP (2008) Feast or famine: the global regulator DasR links nutrient stress to antibiotic production by Streptomyces. EMBO Rep 9:670-675

126. Rodriguez-Garcia A, Sola-Landa A, Apel K, Santos-Beneit F, Martin JF (2009) Phosphate control over nitrogen metabolism in Streptomyces coelicolor: direct and indirect negative control of $g \ln R, g \ln A, g \ln I I$ and $a m t B$ expression by the response regulator PhoP. Nucleic Acids Res 37:3230-3242

127. Romero D, Traxler MF, Lopez D, Kolter R (2011) Antibiotics as signal molecules. Chem Rev 111:5492-5505

128. Sanchez S, Chavez A, Forero A, Garcia-Huante Y, Romero A, Sanchez M, Rocha D, Sanchez B, Avalos M, Guzman-Trampe S, Rodriguez-Sanoja R, Langley E, Ruiz B (2010) Carbon source regulation of antibiotic production. J Antibiot (Tokyo) 63:442-459

129. Santos-Beneit F, Barriuso-Iglesias M, Fernandez-Martinez LT, Martinez-Castro M, Sola-Landa A, Rodriguez-Garcia A, Martin JF (2011) The RNA polymerase omega factor RpoZ is regulated by PhoP and has an important role in antibiotic biosynthesis and morphological differentiation in Streptomyces coelicolor. Appl Environ Microbiol 77:7586-7594

130. Santos-Beneit F, Rodriguez-Garcia A, Sola-Landa A, Martin JF (2009) Cross-talk between two global regulators in Streptomyces: PhoP and AfsR interact in the control of afs $S$, pst $S$ and phoRP transcription. Mol Microbiol 72:53-68

131. Sekurova O, Sletta H, Ellingsen TE, Valla S, Zotchev S (1999) Molecular cloning and analysis of a pleiotropic regulatory gene locus from the nystatin producer Streptomyces noursei ATCC11455. FEMS Microbiol Lett 177:297-304

132. Shapiro S (1989) Nitrogen assimilation in actinomycetes and the influence of nitrogen nutrition on actinomycete secondary metabolism. In: Shapiro S (ed) Regulation of secondary metabolism in actinomycetes. CRC Press, Boca Raton, pp 135211

133. Sidda JD, Corre C (2012) Gamma-butyrolactone and furan signaling systems in Streptomyces. Methods Enzymol 517:7187

134. Skinner R, Cundliffe E, Schmidt FJ (1983) Site of action of a ribosomal RNA methylase responsible for resistance to erythromycin and other antibiotics. J Biol Chem 258:12702-12706

135. Sola-Landa A, Moura RS, Martin JF (2003) The two-component PhoR-PhoP system controls both primary metabolism and secondary metabolite biosynthesis in Streptomyces lividans. Proc Natl Acad Sci USA 100:6133-6138

136. Sola-Landa A, Moura RS, Martín JF (2002) The two-component PhoR-PhoP system controls both primary metabolism and secondary metabolite biosynthesis in Streptomyces lividans. Proc Natl Acad Sci USA 100:6133-6138

137. Sterner DE, Berger SL (2000) Acetylation of histones and transcription-related factors. Microbiol Mol Biol Rev 64:435459

138. Strauss J, Reyes-Dominguez Y (2011) Regulation of secondary metabolism by chromatin structure and epigenetic codes. Fungal Genet Biol 48:62-69

139. Swiatek MA, Gubbens J, Bucca G, Song E, Yang YH, Laing E, Kim BG, Smith CP, van Wezel GP (2013) The ROK family regulator Rok7B7 pleiotropically affects xylose utilization, carbon catabolite repression, and antibiotic production in Streptomyces coelicolor. J Bacteriol 195:1236-1248

140. Swiatek MA, Tenconi E, Rigali S, van Wezel GP (2012) Functional analysis of the $\mathrm{N}$-acetylglucosamine metabolic genes of Streptomyces coelicolor and role in the control of development and antibiotic production. J Bacteriol 194:1136-1144

141. Swiatek MA, Urem M, Tenconi E, Rigali S, van Wezel GP (2012) Engineering of $N$-acetylglucosamine metabolism for improved antibiotic production in Streptomyces coelicolor A3(2) and an unsuspected role of NagA in glucosamine metabolism. Bioengineered 3:280-285

142. Tamehiro N, Hosaka T, Xu J, Hu H, Otake N, Ochi K (2003) Innovative approach for improvement of an antibiotic-overproducing industrial strain of Streptomyces albus. Appl Environ Microbiol 69:6412-6417

143. Tanaka Y, Hosaka T, Ochi K (2010) Rare earth elements activate the secondary metabolite-biosynthetic gene clusters in Streptomyces coelicolor A3(2). J Antibiot 63:477-481

144. Tanaka Y, Komatsu M, Okamoto S, Tokuyama S, Kaji A, Ikeda H, Ochi K (2009) Antibiotic overproduction by $r p s L$ and $r s m G$ mutants of various actinomycetes. Appl Environ Microbiol 75:4919-4922 
145. Titgemeyer F (2007) Carbon and nitrogen regulation in Grampositive bacteria: a tribute to Milton H. Saier, Jr. J Mol Microbiol Biotechnol 12:5-8

146. Titgemeyer F, Reizer J, Reizer A, Saier MH Jr (1994) Evolutionary relationships between sugar kinases and transcriptional repressors in bacteria. Microbiology 140:2349-2354

147. Udwary DW, Zeigler L, Asolkar RN, Singan V, Lapidus A, Fenical W, Jensen PR, Moore BS (2007) Genome sequencing reveals complex secondary metabolome in the marine actinomycete Salinispora tropica. Proc Natl Acad Sci USA 104:10376-10381

148. Uguru GC, Stephens KE, Stead JA, Towle JE, Baumberg S, McDowall KJ (2005) Transcriptional activation of the pathwayspecific regulator of the actinorhodin biosynthetic genes in Streptomyces coelicolor. Mol Microbiol 58:131-150

149. van Wezel GP, Konig M, Mahr K, Nothaft H, Thomae AW, Bibb M, Titgemeyer F (2007) A new piece of an old jigsaw: glucose kinase is activated posttranslationally in a glucose transport-dependent manner in Streptomyces coelicolor A3(2). J Mol Microbiol Biotechnol 12:67-74

150. van Wezel GP, Krabben P, Traag BA, Keijser BJ, Kerste R, Vijgenboom E, Heijnen JJ, Kraal B (2006) Unlocking Streptomyces spp. for use as sustainable industrial production platforms by morphological engineering. Appl Environ Microbiol 72:5283-5288

151. van Wezel GP, McDowall KJ (2011) The regulation of the secondary metabolism of Streptomyces: new links and experimental advances. Nat Prod Rep 28:1311-1333

152. van Wezel GP, McKenzie NL, Nodwell JR (2009) Chapter 5. Applying the genetics of secondary metabolism in model actinomycetes to the discovery of new antibiotics. Methods Enzymol 458:117-141

153. van Wezel GP, Titgemeyer F, Rigali S (2006) Methods and means for metabolic engineering and improved product formation by micro-organisms Patent application WO/2007/094667

154. van Wezel GP, White J, Hoogvliet G, Bibb MJ (2000) Application of redD, the transcriptional activator gene of the undecylprodigiosin biosynthetic pathway, as a reporter for transcriptional activity in Streptomyces coelicolor A3(2) and Streptomyces lividans. J Mol Microbiol Biotechnol 2:551-556

155. Vigliotta G, Tredici SM, Damiano F, Montinaro MR, Pulimeno R, di Summa R, Massardo DR, Gnoni GV, Alifano P (2005) Natural merodiploidy involving duplicated $r p o B$ alleles affects secondary metabolism in a producer actinomycete. Mol Microbiol 55:396-412

156. Vining LC (1992) Secondary metabolism, inventive evolution and biochemical diversity: a review. Gene 115:135-140

157. Vogtli M, Chang PC, Cohen SN (1994) afsR2: a previously undetected gene encoding a 63-amino-acid protein that stimulates antibiotic production in Streptomyces lividans. Mol Microbiol 14:643-653

158. Watrous J, Roach P, Alexandrov T, Heath BS, Yang JY, Kersten RD, van der Voort M, Pogliano K, Gross H, Raaijmakers JM, Moore BS, Laskin J, Bandeira N, Dorrestein PC (2012) Mass spectral molecular networking of living microbial colonies. Proc Natl Acad Sci USA 109:E1743-E1752

159. WHO-Media-centre (2012) Antimicrobial resistance WHO.http:// www.who.int/mediacentre/factsheets/fs194/en/

160. Wietzorrek AM, Bibb (1997) A novel family of proteins that regulates antibiotic production in Streptomyces appears to contain an OmpR-like DNA-binding fold. Mol Microbiol 25:11811184

161. Willey JM, Gaskell AA (2011) Morphogenetic signaling molecules of the streptomycetes. Chem Rev 111:174-187

162. Woodruff HB, Ruger M (1948) Studies on the physiology of a streptomycin-producing strain of Streptomyces griseus on proline medium. J Bacteriol 56:315-321

163. Xu Q, van Wezel GP, Chiu HJ, Jaroszewski L, Klock HE, Knuth MW, Miller MD, Lesley SA, Godzik A, Elsliger MA, Deacon AM, Wilson IA (2012) Structure of an MmyB-like regulator from $C$. aurantiacus, member of a new transcription factor family linked to antibiotic metabolism in actinomycetes. PLoS One 7:e41359

164. Yamada Y, Nihira T (1999) Microbial hormones and microbial chemical ecology. In: Mori $\mathrm{K}$ (ed) Comprehensive natural products chemistry, vol. 8. Elsevier Scientific Publishers, Dordrecht, pp 377-413

165. Yamamoto S, He Y, Arakawa K, Kinashi H (2008) $\gamma$-Butyrolactone-dependent expression of the streptomyces antibiotic regulatory protein gene srrY plays a central role in the regulatory cascade leading to Lankacidin and lankamycin production in Streptomyces rochei. J Bacteriol 190:1308-1316

166. Yang YH, Song E, Willemse J, Park SH, Kim WS, Kim EJ, Lee BR, Kim JN, van Wezel GP, Kim BG (2012) A novel function of Streptomyces integration host factor (sIHF) in the control of antibiotic production and sporulation in Streptomyces coelicolor. Antonie Van Leeuwenhoek 101:479-492

167. Yang YL, Xu Y, Straight P, Dorrestein PC (2009) Translating metabolic exchange with imaging mass spectrometry. Nat Chem Biol 5:885-887

168. Yu Z, Zhu H, Dang F, Zhang W, Qin Z, Yang S, Tan H, Lu Y, Jiang W (2012) Differential regulation of antibiotic biosynthesis by DraR-K, a novel two-component system in Streptomyces coelicolor. Mol Microbiol 85:535-556

169. Zerikly M, Challis GL (2009) Strategies for the discovery of new natural products by genome mining. Chembiochem: Eur J Chem Biol 10:625-633 